\title{
Eliminação dos Impostos sobre as Exportações do Agronegócio e seus Efeitos no Comportamento da Economia*
}

\author{
Niraldo José Ponciano** \\ Antônio Carvalho Campos ${ }^{* * *}$
}

Sumário: 1. Introdução; 2. Metodologia; 3. Resultados e discussão; 4. Conclusão.

Palavras-chave: incidência de tributos; exportações; agropecuária; agroindústria; bem-estar.

Códigos JEL: D58; E62.

Este artigo avalia os impactos da eliminação de impostos sobre as exportações brasileiras. Utiliza-se um modelo computável de equilíbrio geral para simular a reação dos agentes econômicos a essas mudanças. A eliminação dos impostos sobre as exportações promove aumento no nível de exportações primárias e maior competição com atividades destinadas à agroindústria e ao consumo doméstico. Conseqüentemente, ocorre queda na renda das famílias, que, por sua vez, diminuem os gastos com o consumo de alimentos. Houve queda generalizada nos níveis de bem-estar dos consumidores, embora tenha havido elevações no nível de emprego rural e na renda obtida do exterior.

This study evaluates the impacts of the elimination of taxes on Brazilian agricultural exports. A computable general equilibrium model is used to simulate the reaction of the economic agents to those changes. The elimination of the taxes on exports promotes an increase in the level of exports and more competition with agro-industrial activities and domestic consumption. Consequently, there is a fall on the level of family income and, as a result, decreases in the family consumption expenses. There was a generalized fall in the levels of consumers' welfare, even though with gains in the level of rural employment and in the foreign exchange earnings.

\footnotetext{
*Artigo recebido em fev. 2002 e aprovado em jul. 2002.

** Professor da Universidade Estadual do Norte Fluminense, Rio de Janeiro.

${ }^{* * *}$ Professor da Universidade Federal de Viçosa, Minas Gerais.
} 


\section{Introdução}

A economia brasileira vem passando, desde o início da década de 1990, por um processo de reformas econômicas e institucionais, com vistas à retomada do processo de desenvolvimento no contexto da internacionalização e da especialização crescentes que caracterizam o novo padrão de expansão da economia mundial. No entanto, os resultados alcançados ainda são insuficientes para contrabalançar o impacto das pressões competitivas geradas pela abertura econômica. Mais preocupante, entretanto, é que essas mudanças têm afetado mais as empresas de médio e pequeno portes, inibindo o crescimento da produção doméstica, do nível de emprego e das exportações.

A competitividade das atividades exportadoras brasileiras tem sido penalizada por distorções do sistema tributário, as quais contribuem para compor o chamado "Custo Brasil". Com vistas a alcançar maior competitividade, as empresas tentam auferir benefícios fiscais que estão condicionados ao cumprimento de determinadas metas, tais como geração de empregos, aumento da produtividade e ampliação das exportações. Assim, as atividades mais competitivas ou que possuem maior capacidade de exportação são aquelas que deveriam receber maiores incentivos fiscais do governo.

O efeito da desoneração fiscal nas atividades de exportação deve ser diferenciado, dada a inserção relativa de cada atividade doméstica na economia mundial. Quando uma atividade nacional tem participação elevada na quantidade total da mercadoria transacionada no mercado internacional, variações em sua oferta influenciam a formação de seus preços, assim, esse país é um price maker nesse setor. Na situação inversa, o país é considerado um price taker, e o preço é definido pelo comportamento da oferta e da demanda no mercado externo.

Nos mercados em que o país atua como price taker o ganho de rentabilidade advindo da desoneração fiscal é mais facilmente internalizado pela atividade, porque o preço externo é definido exogenamente. O aumento da receita de exportação depende do crescimento da parcela nacional no mercado internacional desse produto. Nas transações internacionais da soja em grão, o Brasil é considerado um price taker porque sua parcela de mercado é relativamente pequena em relação à parcela americana.

Por outro lado, nos mercados em que o país atua como price maker o ganho de rentabilidade, devido à desobrigação fiscal, tende a ser passado ao consumidor externo, o que torna essa atividade mais competitiva. A tendência é o aumento do volume exportado, em razão do deslocamento de concorrentes por meio do crescimento da competitividade nesse mercado. O café e o suco de laranja brasileiros 
podem ser enquadrados nesse tipo de produto, pelo fato de o Brasil ainda ser o maior exportador mundial tanto de café quanto de suco de laranja. Portanto, neste último caso espera-se maior receita total nessas atividades em razão da expansão da exportação, mesmo a preços decrescentes.

O objetivo deste trabalho é avaliar os efeitos da desoneração fiscal sobre as exportações das atividades agropecuárias e agroindustriais no comportamento da economia, principalmente no que diz respeito à redução do déficit comercial.

\section{Metodologia}

Shoven e Whalley (1984) apresentam, de forma sintética, as principais características dos modelos aplicados de equilíbrio geral nas análises relacionadas com a incidência de impostos e do comércio internacional. Shoven e Whalley (1972, 1973, 1974, 1977) foram os primeiros a utilizar procedimentos computacionais em modelos aplicados de equilíbrio geral para o estudo da incidência de impostos nos EUA. O modelo por eles especificado na época era muito agregado, constando de dois agentes e dois setores.

Walley (1982), Whalley (1985) desenvolveu modelos aplicados de equilíbrio geral para analisar os ganhos de bem-estar resultantes da redução e/ou abolição de tarifas e impostos sobre os fluxos de mercadorias entre países. No primeiro estudo, procura determinar os ganhos de bem-estar mundial advindos da redução de tarifas na então Comunidade Econômica Européia - CEE, EUA e Japão. No segundo, procura determinar os ganhos de bem-estar resultantes da abolição das barreiras tarifárias existentes no comércio Norte-Sul. Os resultados apontam que, no primeiro estudo, a CEE e o Japão seriam mais beneficiados pelo movimento em direção ao livre comércio. Entretanto, para o segundo estudo, nos três cenários analisados a abolição das barreiras tarifárias só é favorável ao Sul quando ocorre uma abolição unilateral das barreiras no Norte.

As diferenças entre as agendas de pesquisa desenvolvidas por Shoven e Whalley e de seus seguidores e o presente estudo situam-se fundamentalmente em dois pontos. O primeiro está relacionado com a abrangência da análise, que em seus estudos privilegiam o enfoque multirregional. Nesses casos, os efeitos sobre a economia brasileira são representados pelas médias correspondentes ao resto do mundo ou aos países em desenvolvimento. As particularidades setoriais da economia brasileira são, dessa forma, ofuscadas pelas estatísticas das médias. O segundo refere-se ao foco da análise, que neste estudo está centralizado em mensurar os efeitos diretos e indiretos da desoneração fiscal nas exportações do agronegócio brasileiro. Essas diferenças têm suas origens nas motivações que levaram às definições do ob- 
jeto de estudo. Enquanto Walley (1982), Whalley (1985) estava preocupado com os resultados da Rodada Tóquio de Negociações Multilaterais, o presente estudo preocupa-se em determinar os impactos similares aos da Lei Kandir ${ }^{1}$. Para a realidade brasileira, os desempenhos econômicos dos setores primários e agroindustriais são ainda cruciais para o desenvolvimento da economia. Entretanto, esses mesmos setores apresentam pequena importância relativa para as economias avançadas. Logo, tais diferenças são importantes para justificar a realização de estudos dessa natureza no Brasil.

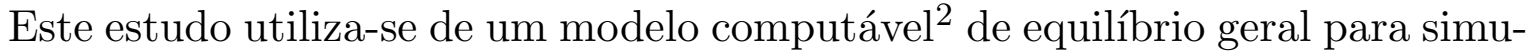
lar a interação entre agentes econômicos, tais como consumidores, firmas, governo e resto do mundo, mediante forças de mercados. Os produtores maximizam lucros sujeitos a restrições tecnológicas, enquanto os consumidores maximizam utilidades sujeitas a restrições orçamentárias. O modelo encontra um vetor de preços e quantidades tal que todos os excessos de demanda sejam eliminados. Nesse modelo, a moeda é neutra e apenas os preços relativos são determinados.

A agregação das atividades prioriza a separação das atividades ligadas ao agronegócio, visto que o objetivo do trabalho é avaliar os impactos de mudanças nas alíquotas de impostos sobre as exportações do agronegócio brasileiro. Nesse sentido, a economia é representada por 20 setores: agropecuária, outros manufaturados, energia, mecânica e elétrica, química, álcool, adubos, fibras têxteis, produtos do café, arroz beneficiado, farinha de trigo, carne bovina, aves abatidas, laticínios, açúcar, óleos vegetais, serviços, serviços financeiros, margem de comércio e transporte e administração pública. Desses setores, 12 estão ligados diretamente ao agronegócio.

O modelo incorpora padrões de substituibilidade e complementaridade no processo de produção, tanto na combinação entre os componentes dos fatores primários como na combinação desses agregados com os insumos intermediários. Os

\footnotetext{
${ }^{1}$ Em 13-9-96, a Lei Complementar n. ${ }^{\circ} 87$ (Lei Kandir) amenizou os efeitos dos impostos efetivamente cobrados sobre esses produtos, mediante a suspensão do ICMS sobre exportação de produtos primários e semi-elaborados (Banco Central Do Brasil - BACEN, 1996).

${ }^{2}$ Baseado nos modelos de Dervis et alii (1984), Brandão et alii (1994), Ferreira Filho, J. B. S. (1995) e Najberg et alii (1995).
} 
produtores escolhem os insumos de produção, otimizando a produção mediante a minimização dos custos.

A figura 1 ilustra a estrutura de produção genérica modelada. Caixas sombreadas especificam as formas funcionais usadas. Duas grandes categorias de insumos são reconhecidas - insumos intermediários e fatores primários. Produtores escolhem os insumos requeridos por unidades de produção, satisfazendo o comportamento de otimização (minimização de custos). As restrições são determinadas pela tecnologia de produção aninhada. Permitem-se combinações, em proporções fixas (Leontief), de insumos intermediários e fatores primários assumidas no primeiro nível (nível superior). No segundo nível, do lado esquerdo, apresentam-se as combinações em proporções fixas (Leontief) entre os insumos disponíveis na própria atividade e outros insumos provenientes do MERCOSUL e Resto do Mundo. Nesse mesmo nível, do lado direito, tem-se a substituição (CES) de capital agregado por trabalho agregado. Logo abaixo encontra-se o terceiro nível, que se refere à substituição (CES) de insumos importados pelos similares produzidos domesticamente. No quarto nível, pacotes de insumos importados, oriundos de diferentes regiões, são combinados mediante agregações (CES).

Figura 1

Estrutura de produção genérica para cada atividade modelada no trabalho

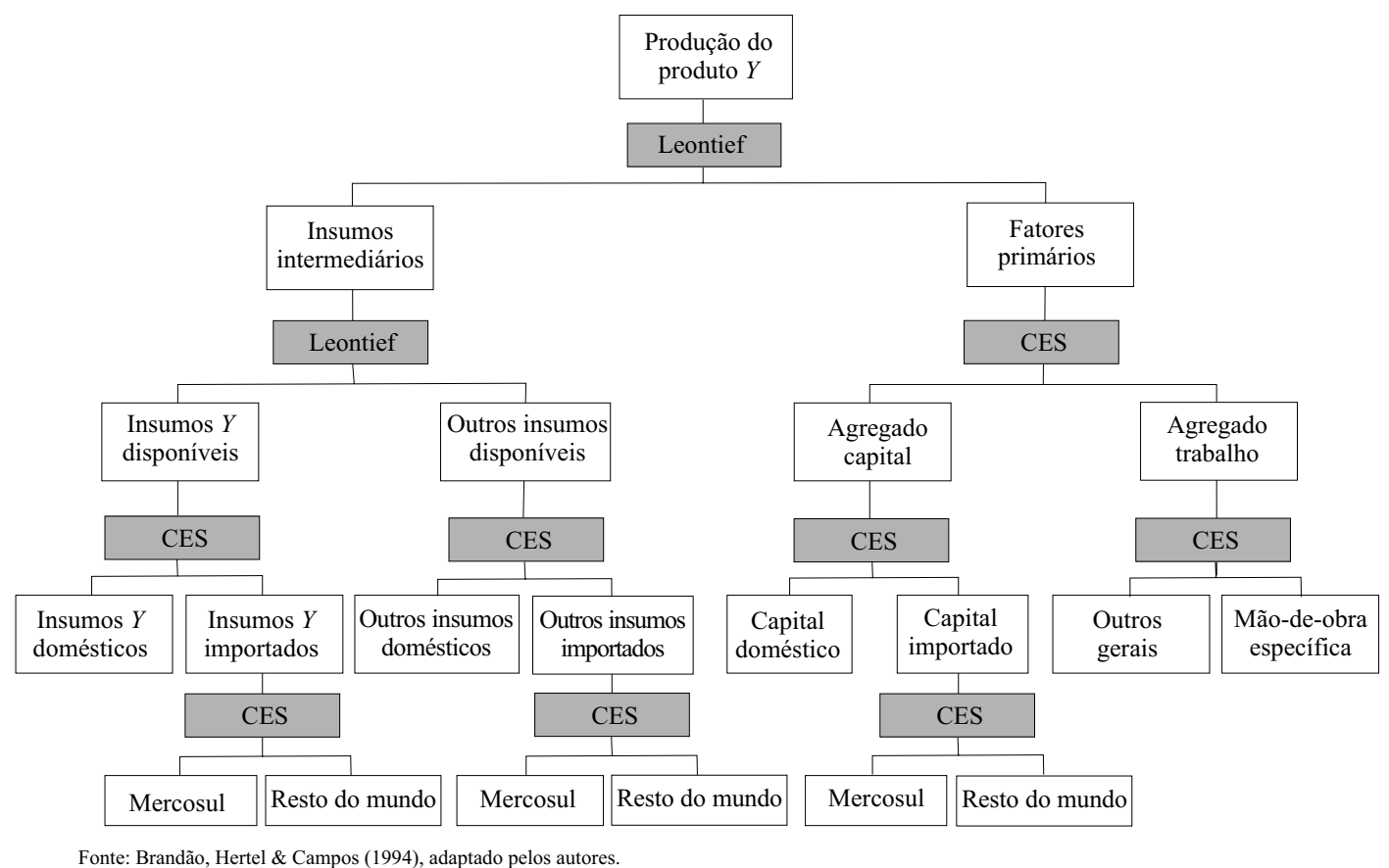

Fonte: Brandão et alii (1994), adaptado pelos autores. 
Dada a natureza estática do modelo, os produtores são impossibilitados de ajustarem seus estoques de capital às mudanças no ambiente econômico. Assim, nas perspectivas de curto ou longo prazo somente um ponto de equilíbrio é captado pelo modelo. Dessa forma, o modelo não incorpora os efeitos da política comercial sobre o crescimento econômico e muito menos os efeitos endógenos dessa política comercial na economia (Dixon et alii, 1992). Para contornar essas restrições, as simulações estático-comparativas são usualmente interpretadas como medidas de efeitos de mudanças na política comercial no curto ou longo prazo. Uma característica distintiva das simulações estático-comparativas no curto e longo prazo é o tratamento que se dá aos estoques setoriais de capital. Nas simulações de curto prazo, assume-se que esses estoques de capital são fixos, ou seja, são mantidos constantes em seus níveis pré-choques. A pressuposição típica para a simulação estático-comparativa de longo prazo é que os estoques de capital devem se ajustar para restabelecer a taxa de rentabilidade do capital (Peter et alii, 1996). Segundo esses autores, as evidências de estudos econométricos sugerem um período de dois anos para os ajustamentos no curto prazo e de seis, 10 ou 20 anos para os ajustamentos no longo prazo. Independente dessas considerações, o presente modelo é atemporal.

Com relação ao setor externo, admite-se que o país venda produtos diferenciados no mercado internacional e que a função de demanda das exportações tenha elasticidade-preço finita. Admite-se que os bens importados sejam substitutos imperfeitos dos bens produzidos domesticamente. Nesse caso, utiliza-se uma mercadoria compósita, que é representada por uma função de agregação do tipo CES, entre bens importados e bens produzidos domesticamente. Partindo-se da relação entre os preços desses dois bens, a solução para o problema de minimização de custos determina a relação insumos importado/doméstico, em que a taxa marginal de substituição entre os mesmos é igual ao preço relativo dos insumos.

No que se refere às equações de demanda, as especificações diferenciam as categorias das famílias e do governo que demandam bens de consumo, enquanto as firmas, por outro lado, demandam bens de capital. Os consumidores maximizam funções de utilidade tipo CES, sujeitos às respectivas restrições orçamentárias.

Em um nível superior, as famílias maximizam sua utilidade pela substituição do consumo presente pelo consumo futuro (poupança). Portanto, a escolha do consumidor ocorre mediante sua expectativa sobre o comportamento da renda futura. Logo abaixo, há substituição de consumo entre alimentos e outros bens. Em nível intermediário, tem-se a utilidade derivada do consumo de bens disponíveis, maximizada pela substituição entre cereais, protéicos e outros produtos alimentícios, como açúcar, café, óleos e demais produtos agropecuários. No nível mais infe- 
rior, há substituição entre a disponibilidade de produtos do arroz e do trigo, no agregado cereais, e a substituição entre carne bovina, carne de aves e laticínios no agregado protéicos.

\subsection{Calibração do modelo e simulação de referência}

De acordo com Mansur e Whalley (1984), citados em Shoven e Whalley (1998), na determinação dos resultados das simulações realizadas com MAEG a definição dos parâmetros das formas funcionais é fundamental. O procedimento mais utilizado para selecionar esses parâmetros é a calibração, que deve ser entendida como um método de estimação de parâmetros de forma que o modelo especificado seja capaz de reproduzir as observações do ano básico como uma solução de equilíbrio deste modelo. Desse modo, o modelo é solucionado a partir das informações obtidas do equilíbrio inicial na Matriz de Contabilidade Social - MCS e de estimativas das elasticidades de substituição na produção e no consumo e das elasticidadespreço da demanda de importações e de exportações para gerar os parâmetros de eficiência, distribuição e substituição das funções CES. ${ }^{3}$ Em contraste com os métodos econométricos estocásticos, que freqüentemente simplificam a estrutura do modelo econômico para permitir a maior riqueza da especificação estatística, o método da calibração, ao optar pela riqueza da estrutura econômica do modelo, faz uma representação estatística não-aleatória, por meio de um modelo determinístico (Shoven e Whalley, 1998).

De acordo com Shoven e Whalley (1998), esse procedimento admite que o fluxo circular especificado na Matriz de Contabilidade Social (MCS), para o anobase, represente uma solução de equilíbrio inicial. A mudança implementada pelos choques externos provoca, então, um processo de reajustamento do sistema (que segue a lógica explícita pelos parâmetros funcionais) até o alcance de nova posição de equilíbrio. Conseqüentemente, a análise do impacto é feita pela comparação entre os valores das variáveis endógenas, nas duas situações otimizadas. O método de calibração, portanto, é mais simples e prático que a estimação econométrica, permitindo maior operacionalidade aos MCEGs, uma vez que os mesmos envolvem a utilização de grande quantidade de parâmetros.

\footnotetext{
${ }^{3}$ No caso da calibração de funções de elasticidade de substituição constante - CES, o algoritmo MPSGE calcula os parâmetros de eficiência, de distribuição e de substituição a partir dos coeficientes técnicos de produção e/ou de consumo existentes na MCS e das estimativas dos coeficientes de elasticidade fornecidos para cada uma das funções especificadas.
} 
O procedimento adotado na execução da pesquisa foi definir o modelo econômico, a agregação dos setores e as atividades a partir da matriz de insumo-produto brasileira. Em seguida, construiu-se a MCS, com dimensão 26x26. Essa MCS foi usada como base de dados para a calibração do modelo utilizado nas simulações desejadas. Para cada simulação, o modelo foi resolvido para as variáveis endógenas, a partir de valores dados para as variáveis exógenas e demais parâmetros. Os fluxos foram alterados e, conseqüentemente, refletiram os efeitos da simulação dos choques sobre as variáveis ligadas ao objeto de estudo.

As informações utilizadas foram retiradas das tabelas de matriz insumo-produto e das Contas Nacionais do Brasil referentes ao ano de 1995. Os demais dados utilizados foram provenientes dos censos econômicos, do Boletim do Banco Central, do AGRIANUAL (1996 a 1999), do ANUALPEC (1996 a 1999) e de outras fontes, de maneira a reproduzir, adequadamente, o fluxo circular da economia brasileira no ano-base de 1995. Os valores dos coeficientes de elasticidades utilizados na calibração do modelo e as respectivas fontes encontram-se nas tabelas do apêndice.

\subsection{Desoneração e efeitos sobre o bem-estar dos consumidores ${ }^{4}$}

As estimativas da variação equivalente foram empregadas para avaliar os efeitos de alterações na incidência de impostos nas exportações. A variação equivalente refere-se à quantia adicional de renda monetária, aos preços relativos do equilíbrio inicial, necessária para manter inalterado o nível de bem-estar dos consumidores, quando estes alcançam diferentes níveis de utilidade, aos preços relativos dados pelas soluções de equilíbrio alternativas.

$$
\text { Cálculo da variação equivalente: } V E=\frac{\left(U^{N}-U^{0}\right)}{U^{0}} I^{0}
$$

em que:

$U^{0}=$ utilidade do agente econômico no equilíbrio inicial;

$U^{N}=$ utilidade do agente econômico no equilíbrio novo;

$I^{0}=$ renda do agente econômico no equilíbrio inicial.

\section{Resultados e Discussão}

Três cenários são implementados com o objetivo de avaliar a competitividade dos produtos exportáveis e os seus efeitos na balança comercial brasileira. $\mathrm{O}$

\footnotetext{
${ }^{4}$ Baseado em Varian (1992). Microeconomics analysis. New York, Norton \& Company. 550 p.
} 
cenário 1 simula um choque da eliminação dos impostos incidentes nas exportações da atividade agropecuária; o cenário 2, um choque da eliminação desses impostos nas exportações das atividades agroindustriais; e o cenário 3, um choque da eliminação simultânea dos impostos incidentes nas exportações dessas atividades.

A eliminação dos impostos nas atividades agropecuárias, em separado ou em conjunto com as atividades agroindustriais, produz efeito depressivo sobre o nível da atividade econômica, com queda no nível de renda das famílias, a qual resulta na diminuição do consumo de alimentos e na receita do governo. Por força da especificação do modelo, os gastos do governo foram mantidos constantes, ou seja, a implementação desses cenários não implica na redução do montante de serviços oferecidos pelo setor público. Para atender aos requerimentos desses serviços, o novo equilíbrio é alcançado pelo crescimento da utilização da poupança externa. Desse modo, faz-se a permuta da possibilidade da tributação doméstica pelo endividamento externo, a fim de compensar a queda observada na receita do governo (figura 2).

Figura 2

Efeitos da implementação dos cenários analíticos sobre indicadores econômicos selecionados

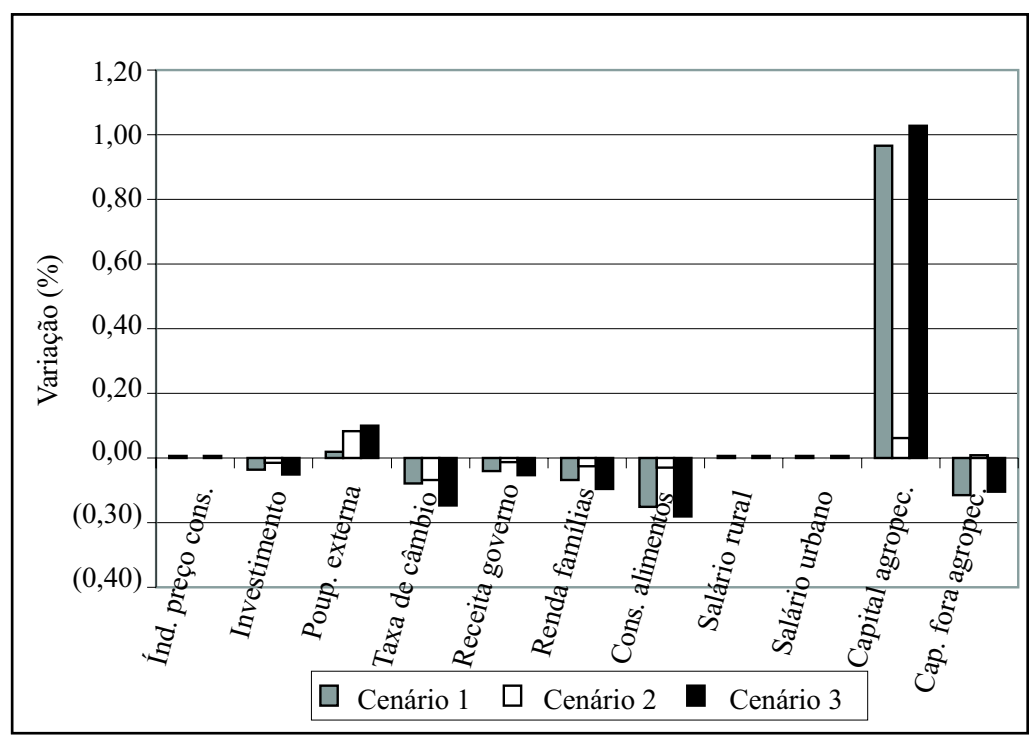


A rentabilidade do capital agropecuário recebe o maior efeito positivo da implementação dos cenários analisados, o que indica que os produtos agropecuários que expandem suas exportações são bastante intensivos em máquinas, equipamentos e insumos químicos e menos intensivos em mão-de-obra, haja vista que os salários continuam inalterados. Considerando as pressuposições sobre os estoques de capital das indústrias e a natureza atemporal do modelo, o crescimento da rentabilidade do capital sinaliza que se devam aumentar os investimentos no capital agropecuário.

Nas atividades produtivas ligadas à agroindústria, o efeito recessivo da implementação desses cenários resulta na redução das quantidades produzidas internamente (figura 3). No caso das atividades agropecuárias e a produtora de adubos, suas produções aumentam em todas as simulações, principalmente naquelas em que há desoneração das exportações agropecuárias. O crescimento da produção de adubos está diretamente relacionado com a expansão da agropecuária, dada a relação de complementaridade existente entre essas atividades. Verificam-se respostas negativas nas atividades agroindustriais quando o choque é direcionado à agropecuária, o que demonstra existir competição pelo produto agropecuário destinado à exportação e por aquele destinado à agroindústria. As agroindústrias ligadas ao processamento de açúcar, arroz, álcool, laticínios, óleos vegetais, trigo e carnes apresentam quedas nos níveis de atividades em todos os cenários analisados. Entretanto, notam-se grandes efeitos positivos nas produções das agroindústrias de têxtil e beneficiamento de café quando a desoneração fiscal é aplicada diretamente nas exportações dessas agroindústrias.

A explicação para tal comportamento pode estar associada ao ganho de competitividade internacional das atividades primárias que fornecem matéria-prima para o processamento agroindustrial doméstico. Na atividade produtora de óleos vegetais esse efeito é mais evidente, visto que há possibilidade, principalmente no caso da soja, de exportação do grão in natura. Conseqüentemente, a partir do momento em que há uma isenção de tributos para as exportações de produtos básicos as agroindústrias de óleos passam a trabalhar com capacidade ociosa, em função do crescimento das exportações de grãos dessas oleaginosas.

A explicação para o comportamento dos setores têxtil e café está relacionada com a restrição na base de dados da matriz de insumo produto do IBGE, que não contempla nas exportações da agropecuária os fluxos de exportações para o algodão em caroço e o café em coco, produtos primários das atividades algodoeira e cafeeira. Dessa forma, desonerar as exportações da agropecuária não resulta em 
nenhum efeito para trás na produção e/ou exportação desses produtos. Entretanto, quando há a desoneração fiscal das exportações no nível dessas agroindústrias observam-se efeitos de ganhos relativos de competitividade nas exportações de seus produtos.

\section{Figura 3}

Efeitos da implementação dos cenários analíticos sobre os níveis de produção doméstica

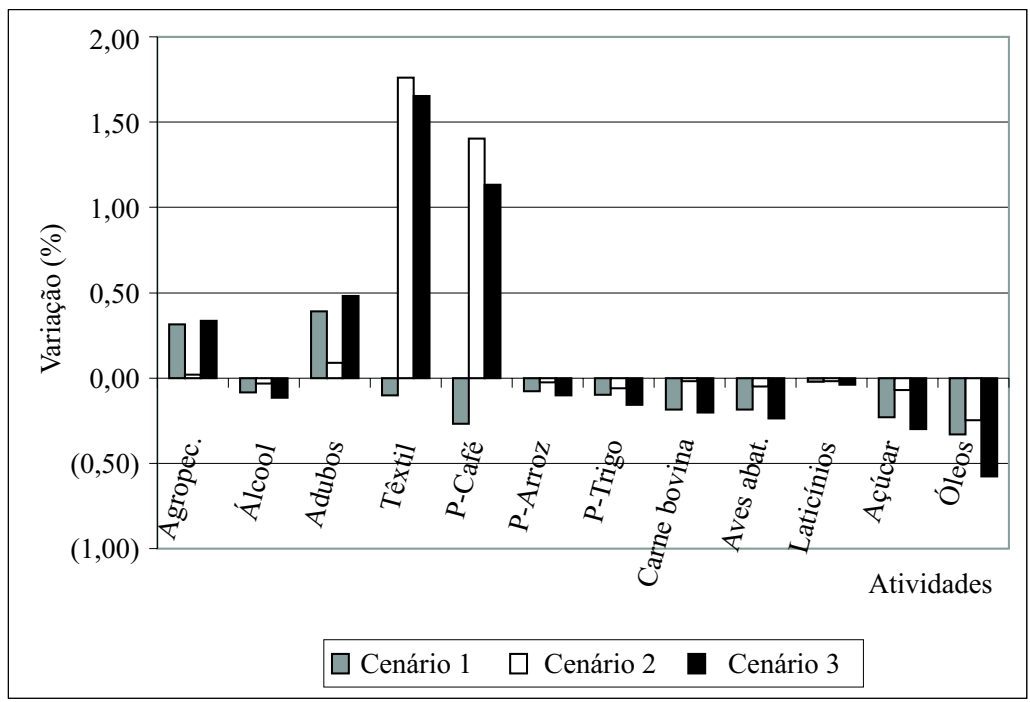

Após conhecer as respostas nos níveis das atividades para os diferentes segmentos das cadeias agroindustriais, o foco da análise volta-se para a determinação dos efeitos sobre seus preços (figura 4). A implementação do cenário 1, além de provocar grande elevação nos preços dos produtos agropecuários (efeito direto), desencadeia efeitos indiretos no aumento de preços em todos os produtos agroindustriais, inclusive superiores em magnitude aos resultantes da desoneração fiscal das exportações dos produtos agroindustriais (cenário 2). Isso ocorre pelo fato de a agroindústria possuir grande dependência da agropecuária, como fornecedora de matéria-prima, direta e indiretamente. Como foi visto, a retirada dos impostos incidentes nas exportações de produtos primários provoca uma expansão de suas exportações. A tributação antes existente favorecia a formação interna de um mercado cativo para as matérias-primas agropecuárias. Tomando a agroindústria da soja como exemplo, tem-se que ao restringir a oferta doméstica de soja em grão há uma elevação no seu preço interno que, por sua vez, afeta diretamente os custos de produção de óleos vegetais e de ração animal e, indiretamente, os custos de produção de carnes e de laticínios. 
Chama-se atenção, novamente, para as respostas das atividades produtoras de adubos e têxtil, cujos preços diminuíram em função da desoneração fiscal das exportações de produtos agropecuários. No caso de adubos, o crescimento da demanda interna não provocou aumento no preço em função da facilidade em complementar a oferta doméstica com as importações dessa mercadoria. Para o setor têxtil, o aumento da disponibilidade interna foi facilitado pela possibilidade da importação com tarifa zero dos países do MERCOSUL, o que pode ter tido um impacto estabilizador sobre seus preços.

Figura 4

Efeitos da implementação dos cenários analíticos sobre os preços domésticos

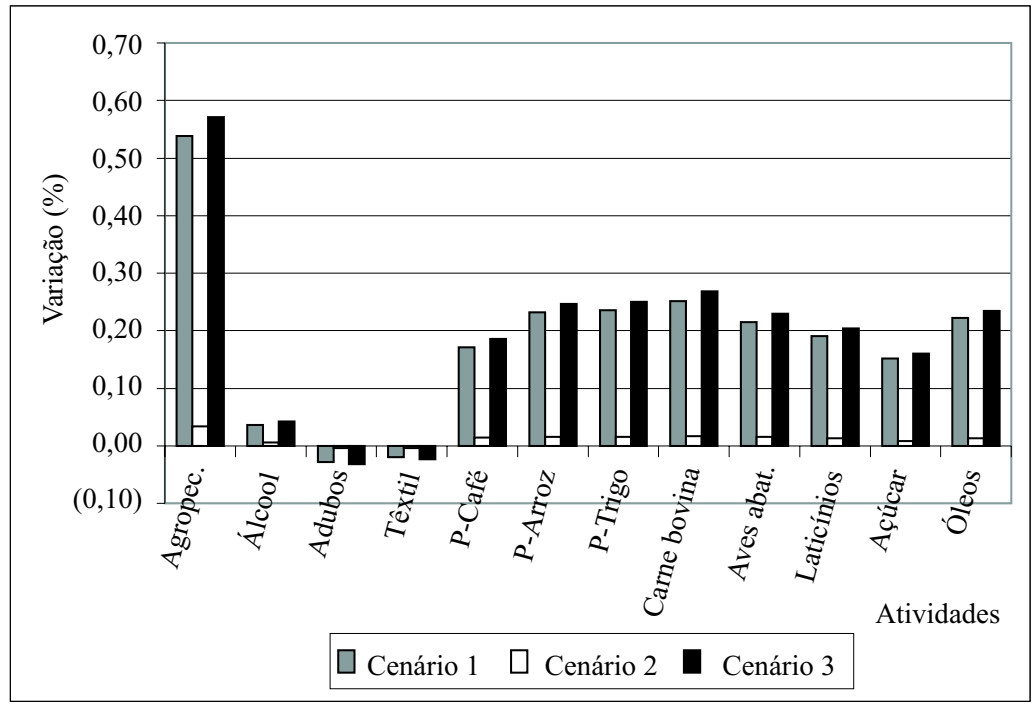

A eliminação do imposto sobre as exportações funciona como um subsídio, deslocando para a direita a curva de oferta das exportações, expressa em unidades de moedas estrangeiras. As pequenas elevações de preços agroindustriais resultantes da implementação dos três cenários revelam que a adoção dessa medida de política não se constitui em obstáculo ao crescimento das exportações agroindustriais. No entanto, essa medida de política é útil para tornar mais transparentes os sinais do mercado externo, que já se encontra com seus preços aviltados em função do protecionismo existente, principalmente, na União Européia e nos EUA. 
Os efeitos conjuntos das variações nos preços e quantidades podem ser observados nos valores da produção doméstica (figura 5), quando os efeitos finais para a maior parte das atividades situam-se próximos de zero. As exceções ficam com os valores da produção da agropecuária, adubos, têxtil e café, que refletem os efeitos já comentados anteriormente. Como se pode depreender, a implementação dessa medida de política não causa alterações marcantes na composição produtiva do agronegócio brasileiro.

Por outro lado, quando se considera que a tributação das exportações constitui um meio de restringir a participação brasileira no mercado externo e que a competitividade da agropecuária pode ser incrementada por meio de novos investimentos (veja rentabilidade do capital na figura 2), conclui-se que a desoneração fiscal das atividades do agronegócio só traz benefícios para o setor.

O estímulo à exportação de produtos primários e processados compete com a oferta oferta doméstica desses produtos. Ao reduzir a oferta interna de produtos processados, as necessidades domésticas passam a ser satisfeitas por meio do crescimento das importações (figura 6). Os aumentos das importações de agropecuários e adubos devem-se ao crescimento da produção de agropecuários para a exportação. Como já comentado, a indústria têxtil intensifica a produção por meio do crescimento das importações, a partir da desoneração fiscal da agroindústria.

Figura 5

Efeitos da implementação dos cenários analíticos sobre os valores da produção

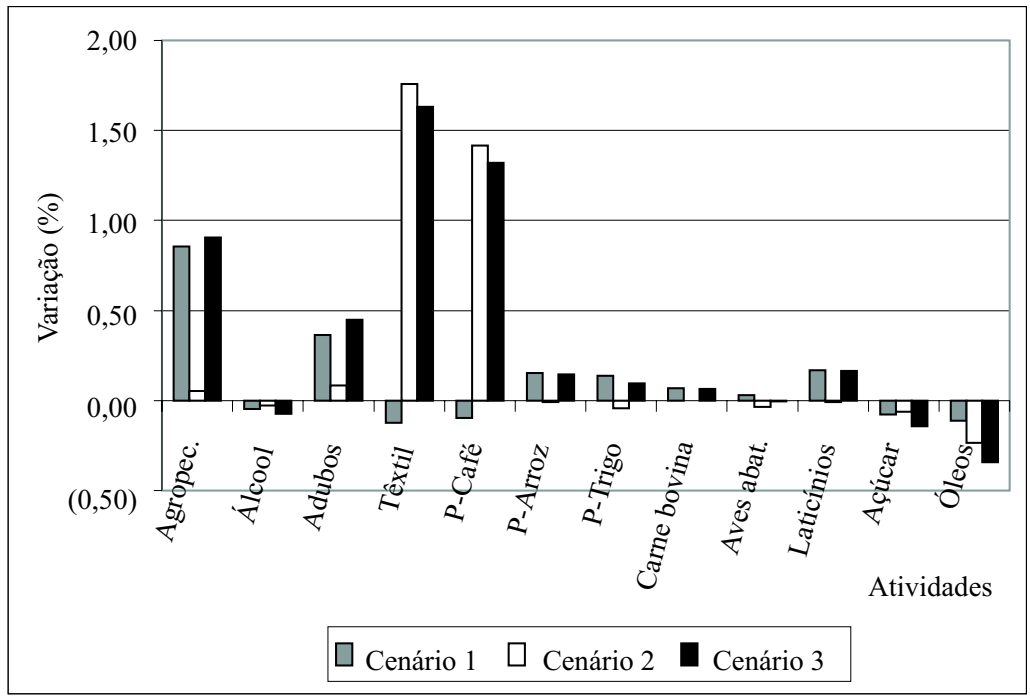


Figura 6

Efeitos da implementação dos cenários analíticos sobre os valores das importações

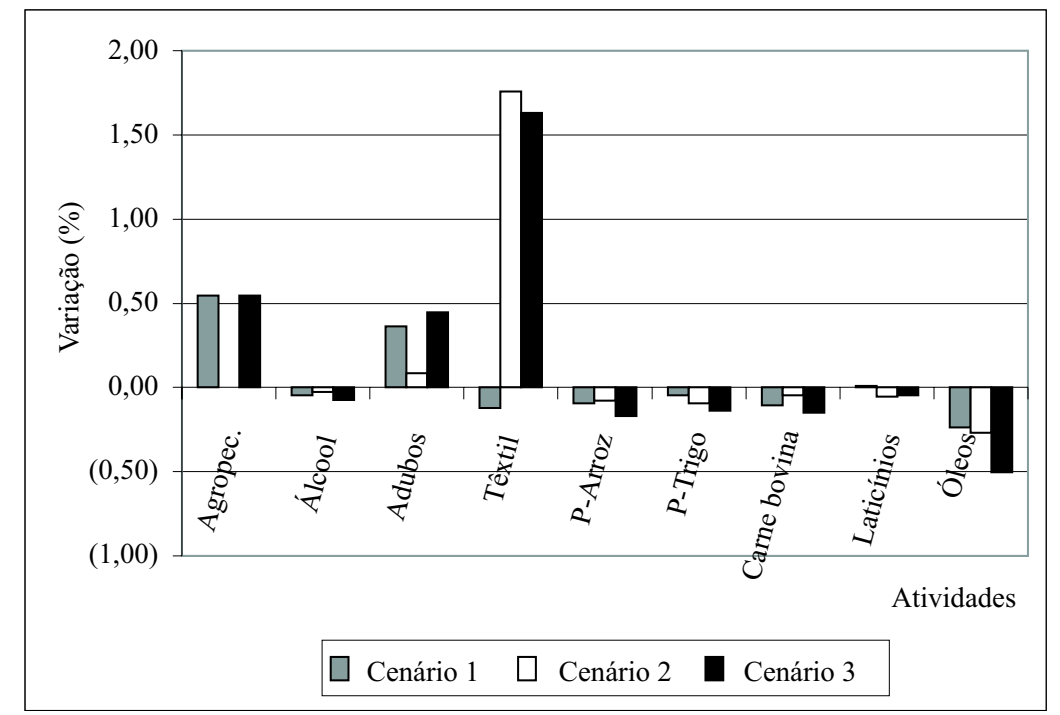

As demais atividades apresentam pequenas quedas nos gastos com importação para todos os cenários, merecendo destaque as importações de óleos vegetais, que se reduzem de forma mais significativa. Esse comportamento reforça os argumentos anteriores, dada a competitividade das importações de produtos agropecuários, principalmente soja em grãos, para abastecer as agroindústrias domésticas e/ou para reexportação em condições mais competitivas do que para o óleo. Nas outras atividades, praticamente não se observam efeitos sobre as importações resultantes da implementação desses cenários, sinalizando que essas importações são usadas apenas para complementar as necessidades do consumo doméstico.

No que se refere às exportações, é interessante observar as mudanças ocorridas para os valores das exportações da agropecuária e da agroindústria têxtil (figura 7). As magnitudes dessas variações, em face da relativa estabilidade das exportações das outras atividades, constituem indicação clara de que a geração de divisas pelo agronegócio brasileiro pode ser aumentada pela eliminação da taxação sobre suas exportações. Esse fato indica que essas exportações apresentam alta sensibilidade às variações de preços, contrariando o pensamento vigente de que as demandas dessas exportações seriam preço-inelásticas.

A eliminação da tributação na agroindústria possibilita o crescimento das exportações de adubos, mas esse resultado fica dependente da importação de matériaprima para esse setor. As variações nas demais exportações são relativamente pequenas em face do crescimento das exportações agropecuárias. Esse resultado 
sugere que as facilidades de exportação dos produtos primários deveriam ser mais bem exploradas com a expansão da produção setorial, de forma a não provocar efeitos negativos nas exportações dos produtos agroindustriais. A efetivação desse potencial exportador da agropecuária pode-se constituir em um fator importante para suavizar a restrição de divisas na economia brasileira.

\section{Figura 7}

Efeitos da implementação dos cenários analíticos sobre os valores das exportações

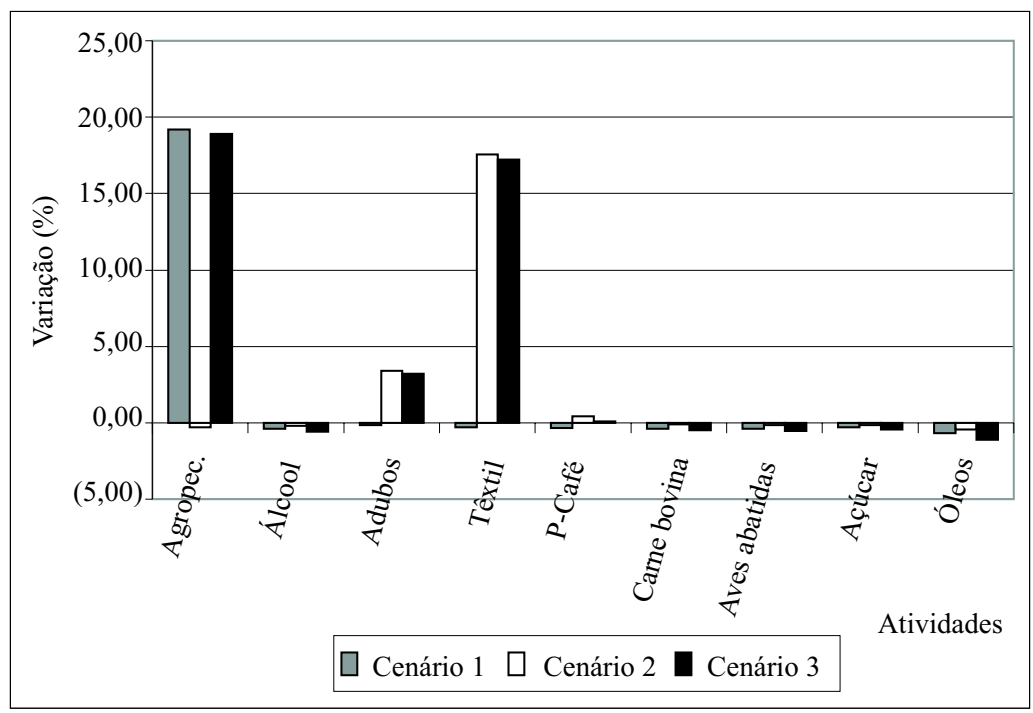

Quando se desoneram as exportações das agroindústrias (cenário 2) constatase, também, que há uma queda nas exportações de óleos vegetais. Uma explicação plausível para esse comportamento pode estar vinculada à maior competição entre as atividades setoriais, ou seja, o crescimento desigual da produção nessas atividades, em resposta à desoneração fiscal (efeito preço) de suas exportações, resulta em uma nova situação competitiva pelos recursos produtivos. No caso, a competitividade relativa da agroindústria de óleos vegetais ficou menor.

Após análise dos efeitos da eliminação das alíquotas do imposto de exportação sobre os fluxos comerciais, torna-se mais fácil justificar a tendência de apreciação da taxa de câmbio (figura 2). Esse comportamento deve-se, em parte, ao fato de o aumento no valor das exportações ser superior ao aumento no valor das importações, o que determina, dessa forma, um crescimento na entrada líquida de divisas.

Em relação ao mercado de trabalho, a suspensão dos impostos de exportação sobre os produtos agropecuários (cenário 1) provoca redução considerável no de- 
semprego rural, dada a expansão da produção para exportação (figura 8). Percebese, no entanto, um ligeiro aumento no desemprego urbano, em razão da queda no nível da atividade agroindustrial processadora de matéria-prima de origem agropecuária. A desoneração fiscal nas exportações agroindustriais (cenário 2) não promove grandes mudanças nos níveis de emprego rural e/ou urbano. A pequena queda no desemprego rural pode estar, provavelmente, associada aos efeitos secundários resultantes do crescimento das exportações da indústria têxtil.

Figura 8

Efeitos da implementação dos cenários analíticos sobre os mercados de trabalho

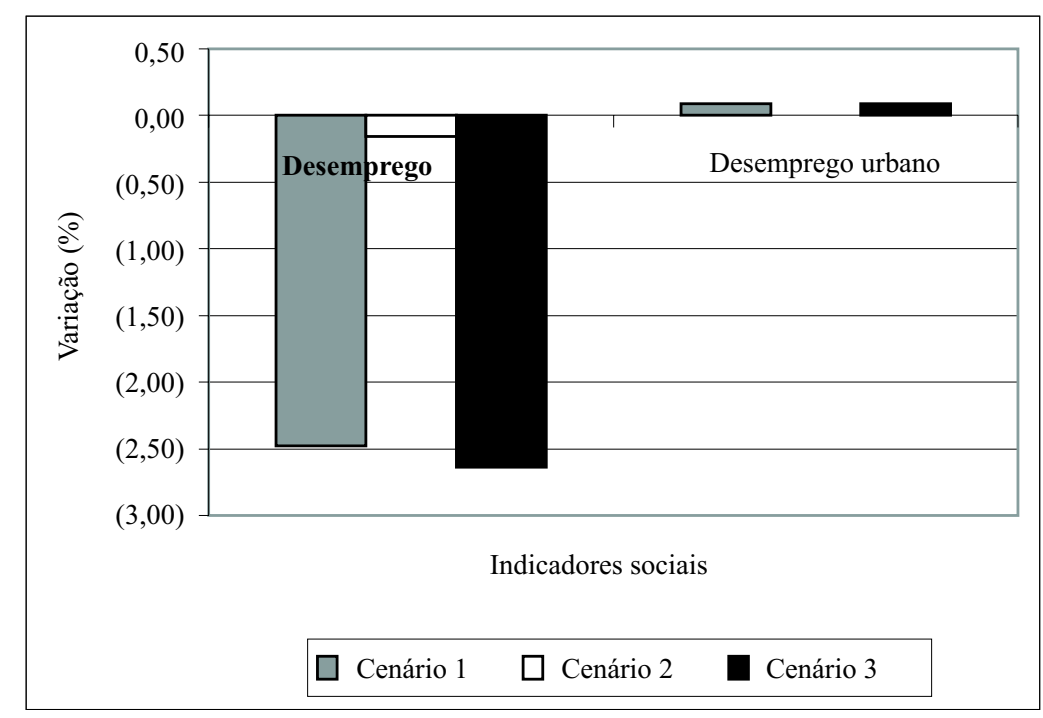

Quanto aos efeitos distributivos, as estimativas dos valores para a variação equivalente indicam, para os três cenários analisados, que houve reduções nos níveis de satisfação dos consumidores (tabela 1). A desoneração fiscal das exportações do agronegócio brasileiro, na ausência de novos investimentos na agropecuária, não gera efeitos positivos em termos de bem-estar econômico. Esses resultados sugerem que o aproveitamento do potencial exportador do agronegócio não pode ficar restrito à adoção de medidas relacionadas exclusivamente com mudanças na política comercial. Para que haja um efeito de extravasamento positivo sobre o resto da economia, faz-se necessário que essa medida venha acompanhada de mudanças em variáveis determinantes dos níveis de novos investimentos. 
Tabela 1

Efeitos da eliminação de impostos em exportações selecionadas sobre o bem-estar dos consumidores, em milhões de reais

\begin{tabular}{lclllll}
\hline & \multicolumn{3}{c}{ Renda das famílias } & \multicolumn{3}{c}{ Renda do exterior } \\
\cline { 2 - 7 } \multicolumn{1}{c}{ Discriminação } & Total & $\begin{array}{c}\text { Variação } \\
\text { equivalente }\end{array}$ & $(\%)$ & $\begin{array}{c}\text { Total } \\
\text { equivalente }\end{array}$ & Variação & $(\%)$ \\
& $406.636,82$ & 0 & 0 & $81.490,89$ & 0 & 0 \\
Equilíbrio inicial & $406.388,71$ & $-248,11$ & $-0,06$ & $81.661,08$ & 170,19 & 0,21 \\
Cenário 1 & $406.539,96$ & $-96,86$ & $-0,02$ & $81.728,92$ & 238,03 & 0,29 \\
Cenário 2 & $406.293,55$ & $-343,27$ & $-0,08$ & $81.899,11$ & 408,22 & 0,50 \\
Cenário 3 & & & & & & \\
\hline
\end{tabular}

Fonte: dados da pesquisa.

A eliminação dos impostos sobre as exportações de produtos agropecuários e agroindustriais resulta, no entanto, no aumento do nível de entrada de divisas externas, em relação ao equilíbrio inicial, para todos os cenários considerados. Portanto, a realização de uma reforma tributária que utilize instrumentos da política comercial para a desoneração fiscal das exportações do agronegócio deve ser considerada como uma variável relevante na promoção do comércio externo brasileiro, quando se deseja aumentar o nível de receita proveniente do exterior.

\section{Conclusão}

A eliminação dos impostos sobre as exportações dos produtos agropecuários, em separado ou em conjunto com as exportações dos produtos agroindustriais, produz um pequeno efeito recessivo sobre o nível da atividade econômica brasileira, com queda no nível de renda das famílias. Essa queda na renda das famílias resulta na diminuição do consumo de alimentos e na receita do governo.

A rentabilidade do capital agropecuário recebe o maior efeito positivo da implementação dos cenários analisados. Isso indica que os produtos agropecuários que expandem suas exportações são bastante intensivos em máquinas, equipamentos e insumos químicos e pouco intensivos em mão-de-obra, haja vista que os salários continuam inalterados. Quando o choque é direcionado somente à agropecuária, verificam-se respostas negativas nas atividades agroindustriais, o que demonstra a existência de competição entre usos do produto agropecuário destinado à exportação e como fonte de matéria-prima para a agroindústria. Nas atividades produtivas ligadas à agroindústria, o efeito recessivo da implementação desses cenários resulta na redução das quantidades produzidas internamente.

As magnitudes de variações nos valores das exportações indicam alta flexibilidade-preço, resultante de mudanças na incidência do imposto de exportação para 
os produtos agropecuários e têxteis, em razão da forte expansão dos preços recebidos pelos produtores nessas atividades. Dessa forma, a eliminação do imposto sobre as exportações dos produtos da agropecuária e das agroindústrias têxtil, adubos e café torna essas atividades mais competitivas no mercado externo.

Em termos gerais, a eliminação do imposto de exportação sobre os produtos da agropecuária e da agroindústria promove uma tendência de apreciação da taxa de câmbio real. Esse comportamento ocorre, em parte, em razão de o aumento no valor das exportações ser superior ao aumento no valor das importações, determinando, dessa forma, um saldo positivo na entrada de divisas.

A eliminação dos impostos de exportação sobre os produtos agropecuários provoca redução considerável no desemprego rural, dada a expansão das exportações de produtos dessa atividade. Constata-se, no entanto, aumento no desemprego urbano, em virtude da queda no nível de outras atividades, principalmente na maioria das agroindústrias processadoras de matéria-prima de origem agrícola.

Finalmente, a queda no nível de renda das famílias resulta na diminuição do consumo de alimentos, o que, conseqüentemente, promove reduções nos níveis de bem-estar dos consumidores para todos os cenários que desoneram as exportações. A ocorrência desses efeitos em sentido contrário, redução do bem-estar dos consumidores domésticos e aumento das receitas com as exportações, implica que a sociedade deve escolher, em dado momento, o rumo da orientação política a ser seguido nas suas relações com o exterior.

\section{Referências}

Anuário Estatístico do Brasil (1990 a 1998). Rio de Janeiro, IBGE.

Banco Central Do Brasil - BACEN (1996). Boletim do Banco Central do Brasil. Brasília, D.F., 243 p. (relatório).

Brandão, A. S. P., Hertel, T., \& Campos, A. C. (1994). Distributional implications of agricultural liberalization: A case study of Brazil. In Goldin, I. \& Knudsen, O. \& Brandão, A. S. (Eds.), editor, Modeling Economy - Wide Reforms, page 296. OECD/Development Centre Studies, Paris.

Dervis, K., de Melo, J., \& Robinson, S. (1984). General Equilibrium Models for Development Policy. Cambridge University, Cambridge. 526 p. (World Bank Research Publications).

Dixon, P. B., Parmenter, B. R., Powell, A. A., \& Wilcoxen, P. J. (1992). Notes 
and problems in applied general equilibrium economics. Amsterdam: NorthHolland, 392p.

Ferreira Filho, J. B. S. (1995). Megabrás - um modelo de equilíbrio geral computável aplicado à análise da agricultura brasileira. São Paulo, USP, 171p. Tese (Dutorado em Economia) - Universidade de São Paulo.

Mansur, A. H. \& Whalley, J. (1984). Numerical specification of applied general equilibrium models: Estimation, calibration and data. In Scarf, H. E. \& Shoven, H. E., editors, Applied General Equilibrium Analysis. Cambridge University Press, Cambridge.

Najberg, S., Rigolon, F. J. Z., \& Vieira, S. P. (1995). Modelo de equilíbrio geral como instrumento de política econômica: Uma análise de câmbio x tarifas. Rio de Janeiro, BNDES, 24 p. (Textos para discussão, 30).

Peter, M. W., Horridge, M., Meagher, G. A., Naqvi, F., \& Parmenter, B. R. (1996). The theoretical structure of MONASH-MRF. Centre of Policy Studies, Monash University. Preliminary Working Paper No. OP-85, April.

Shoven, J. B. \& Whalley, J. (1972). A general equilibrium calculation of the effects of diferential taxation of income from capital in the U.S. Journal of Public Economics, 1:281-322.

Shoven, J. B. \& Whalley, J. (1973). General equilibrium with taxes: A computation procedure and an existence proof. Review of Economic Studies, 40:475-90.

Shoven, J. B. \& Whalley, J. (1974). On the computation of competitive equilibrium on international markets with tariffs. Journal of International Economics, 4:341-54.

Shoven, J. B. \& Whalley, J. (1977). Equal yield tax alternatives: General equilibrium computational techniques. Journal of Public Economics, 8:211-24.

Shoven, J. B. \& Whalley, J. (1984). Applied general equilibrium models of taxation and international trade: An introduction and survey. Journal of Economic Literature, 22:1007-51.

Shoven, J. B. \& Whalley, J. (1998). Applying General Equilibrium. Cambridge University, Cambridge, 3 edition. 299 p. 
Sousa, M. C. S. (1984). Evaluation économique du programme national de l'Alcool (PNA) au Brésil: Une analyse d'equilibre general. Bruxelles: Université Libre de Bruxelles. 301 p. Tese (Doutorado em Ciências Econômicas).

Varian, H. R. (1992). Microeconomics Analysis. Norton \& Company, New York, third edition.

Walley, J. (1982). An evaluation of the recent Tokyo round trade agreement using general equilibrium computation methods. Journal of Policy Modelling, 4:34161.

Whalley, J. (1985). Trade Liberalization Among Major World Trading Areas. MIT Press, Cambridge: MA. 


\section{Anexo A}

Tabela A.1

Elasticidades de substituição entre produtos domésticos e importados

\begin{tabular}{lc}
\hline \multicolumn{1}{c}{ Discriminação } & Valor do coeficiente \\
\hline Agropecuária & 0,5 \\
Álcool & 0,5 \\
Arroz beneficiado & 1,1 \\
Óleos & 1,1 \\
Carnes & 1,1 \\
Laticínios & 1,1 \\
Adubos & 3,0 \\
Têxtil & 2,5 \\
Energia & 0,3 \\
Outras manufaturas & 1,1 \\
Serviços & 0,3 \\
Transporte & 0,3 \\
\hline Fonte: adaptado de Brandão et alii (1994) e Ferreira Filho, J. B. S. (1995).
\end{tabular}

Tabela A.2

Elasticidades de substituição na função de produção agropecuária

\begin{tabular}{lccc}
\hline \multirow{2}{*}{ Discriminação } & \multicolumn{3}{c}{ Valor do coeficiente } \\
\cline { 2 - 4 } & $\sigma_{1}$ & $\sigma_{2}$ & $\sigma_{3}$ \\
\hline Agropecuária & 0,33 & 0,9 & 0 \\
\hline Fonte: cálculos dos autores. & &
\end{tabular}

Tabela A.3

Elasticidades de substituição na função de preferência das famílias

\begin{tabular}{|c|c|c|c|c|c|c|}
\hline \multirow[t]{2}{*}{ Discriminação } & \multicolumn{6}{|c|}{ Valor do coeficiente } \\
\hline & $\sigma_{1}$ & $\sigma_{2}$ & $\sigma_{3}$ & $\sigma_{4}$ & $\sigma_{5}$ & $\sigma_{6}$ \\
\hline Agropecuária & & & & & & \\
\hline Arroz beneficiado & 3,00 & & & & & 0,00 \\
\hline Farinha de trigo & 3,00 & & & & & 0,00 \\
\hline Carne de aves & & 3,00 & & & & 0,00 \\
\hline Outras carnes & & 3,00 & & & & 0,00 \\
\hline Produtos lácteos & & & 3,00 & & & 0,00 \\
\hline Açúcar & & & & 0,50 & & 0,00 \\
\hline Óleo & & & & 0,50 & & 0,00 \\
\hline Café & & & & 0,50 & & 0,00 \\
\hline Álcool & & & & & 0,30 & 0,00 \\
\hline Alimentos & & & & & & 0,00 \\
\hline Energia & & & & & & 0,00 \\
\hline Outras manufaturas & & & & & & 0,00 \\
\hline Transporte & & & & & & 0,00 \\
\hline Serviços & & & & & & 0,00 \\
\hline
\end{tabular}


Tabela A.4

Elasticidades-preço da demanda de exportações

\begin{tabular}{lc}
\hline \multicolumn{1}{c}{ Discriminação } & Valor do coeficiente \\
\hline Agropecuária & 2,0 \\
Café beneficiado & 1,5 \\
Álcool & 2,5 \\
Açúcar & 1,5 \\
Óleo & 2,0 \\
Carne bovina & 1,5 \\
Carne de aves & 1,5 \\
Fertilizantes & 2,0 \\
Têxtil & 3,0 \\
Energia & 2,0 \\
Outras manufaturas & 2,5 \\
Serviços & 2,0 \\
Serviços financeiros & 3,0 \\
Comércio e transporte & 2,5 \\
\hline Fonte: Adaptado de Brandão et alii (1994) e Ferreira Filho, J. B. S. (1995).
\end{tabular}

